\title{
Environmental and social instruments of public policy in the transition to sustainable development
}

\author{
Elena Abanina, ${ }^{1, *}$, Yulia Sergeenko ${ }^{1}$, Dmitry Petrov ${ }^{1}$, Yulia Litvinova $^{2}$, and Natalia \\ Bobrakova $^{2}$ \\ ${ }^{1}$ Saratov State Law Academy, Saratov, Russia \\ ${ }^{2}$ Leningrad State University named after A.S. Pushkin, Pushkin, Russia
}

\begin{abstract}
The article examines the problems of the formation of state policy in the context of the transition to sustainable development in terms of the search for new tools for its implementation. The authors analyzed modern factors influencing the formation of environmental and social policy in the field of achieving sustainable development goals. The factors that influence the process of achieving sustainable development goals in environmental policy are identified: environmental, organizational, legal and political. Also noted are the factors of a legal and political nature that affect governmental social policy. in the field of achieving sustainable development. New environmental and social instruments of modern governmental policy in the context of the transition to sustainable development have been developed: environmentalization and socialization of economic activity. Key words: sustainable development, ecologization of economic activity, socialization of economic activity.
\end{abstract}

\section{Introduction}

A little over a year has passed since the publication of data on the process and progress in achieving the Sustainable Development Goals (hereinafter also SDGs) prepared by UN experts for each of the 17 goals [1]. This means that society can take stock of the validity of the experts' conclusions and the effectiveness of the measures introduced to improve the process of achieving the SDGs. Achieving the Sustainable Development Goals requires transforming financial, economic and political systems to guarantee human rights for all. Taking into account that the experts and the Secretary-General of the United Nations found the pace of progress towards achieving the set goals insufficient, the authors of this article seem to be able to contribute to the overall process by proposing new tools to improve the situation in certain areas.

The transition to sustainable development should ensure a long-term balanced solution to the problems of socio-economic development, preservation of a favorable environment and natural resource potential, and meeting the needs of the present and future generations of people. Thus, the concept of sustainable development links together the environment,

\footnotetext{
* Corresponding author: elena-abanina@yandex.ru
} 
society and the economy. However, taking into account the current state of the economic, environmental and social spheres, one can draw attention to the fact that the economy does not experience such a load as the environmental and social spheres. In this regard, there is a need to study modern problems affecting the formation of environmental and social policy in the field of achieving sustainable development goals in terms of maintaining their balance.

The aim of this work is to develop environmental and social instruments of modern public policy in the context of the transition to sustainable development.

\section{Materials and methods}

In the study of environmental and social instruments of modern state policy in the context of the transition to sustainable development, we proceeded from the understanding of sustainable development as such a development in which the needs of present generations are met by creating a sustainable "green" economy, rational sustainable use of natural resources, and at the same time the needs future generations are not compromised [2].

We put forward a hypothesis that, given the limited time frame for achieving the SDGs, it is necessary to talk not about individual instruments of state policy in achieving the set goals in certain areas, but about the development of such instruments that allow achieving goals while maintaining a balance of all interests. At the moment, in the conditions of insufficient development of the environmental and social sphere, there is a need to develop environmental and social instruments of state policy in the context of the transition to sustainable development, while excluding their priority over each other.

To develop environmental and social instruments of governmental policy in the context of the transition to sustainable development, the following methods were used:

the dialectical method (when considering the categorical series of the institute "sustainable development", accompanying categories "ecological component of sustainable development", "social component of sustainable development") ";

methods of analysis and synthesis (when identifying factors influencing the formation of environmental and social policy in the field of achieving sustainable development goals);

systemic and structural method (for the development of measures (methods) of greening and socialization of economic activity as instruments of state policy).

\section{Results and discussion}

Sustainable development is fully ensured through the implementation of all envisaged measures in its three components in total.

The economic component of sustainable development consists in the optimal use of natural resources, including their extraction, procurement, collection, processing while maintaining their ecological value.

The ecological component of sustainable development should fully guarantee the safety of all natural resources and ensured by their ecological value. For example, a natural feature such as a forest prevents land degradation and desertification, reduces the risk of floods, forests are necessary for the functioning of main catchments and affect the rainfall regime; maintaining clean air, reducing the risk of landslides, avalanches, droughts, dust and sand storms and other natural disasters; biodiversity conservation (forests and woodlands contain more than 60,000 tree species and, according to UN experts, forests are home to 80 percent of all terrestrial biological species). Under the conditions of global climate change, the role of Russian forests as a carbon sink is increasing. The absorption of carbon by Russian 
forests in recent years has been estimated at between 200 and 400, and even 600 million tons per year.

The social component of sustainable development is ensured by taking into account all possible interests of organizations and groups of people in the process of using all natural resources, their protection, protection and reproduction of renewable resources. For example, UN experts estimate 1.6 billion people, or 25 percent of the world's population, depend on natural resources for livelihoods, livelihoods, employment and incomegenerating activities.

Having studied the current state of the economic, environmental and social component, we drew attention to the fact that in terms of the economic sphere, despite the economic crisis associated with the pandemic, the economy of natural resources does not experience such a burden as the environmental and social spheres. In this regard, we have studied modern factors influencing the formation of environmental and social policy in the field of achieving sustainable development goals.

1. Environmental policy:

Environmental factors:

— violation of biological diversity (due to the destruction of rare animals and plants);

— insufficient efficiency of restoration, protection and protection of natural resources.

Organizational factors:

— insufficient accuracy of accounting for natural resources;

- low relevance of information about natural resources;

- excessive administrative barriers;

- poorly developed infrastructure, including road one;

- low level of technical, scientific and personnel support for many natural resource industries.

Legal and political factors:

— imperfection of the legal framework in the natural resource complex and related industries;

- a high level of shadow turnover of natural resources (animals, forests, minerals);

- high latency of environmental violations.

2. Social policy.

The prevailing number of cases related to the violation of the social rights of the population are associated with factors of a legal and political nature:

- lack of legal regulation of socially significant issues (lack of order and form of participation of the local population in the preparation of decisions, the implementation of which may have an impact on nature during its use);

- insufficient regulation of the use of natural resources by the local population for their own needs;

- the lack of regulations on the preservation of natural areas that are of particular importance to the local population (for example, recreation sites, local reservoirs for fishing, places for collecting medicinal herbs, berries, mushrooms; hunting places);

- high differentiation of the level of income of different strata and groups of the population.

These circumstances indicate that in the context of the intensification of the process to achieve sustainable development goals in the environmental and social spheres, new, adequate response measures are needed.

In our opinion, given the limited time frame for achieving the SDGs - 2030, it makes sense to talk not just about recommendatory, "soft" measures, but to introduce clear restrictive, prohibitive, mandatory requirements. At the moment, in the conditions of 
insufficient development of the ecological and social sphere, we propose such measures as the greening and socialization of economic (economic) activities.

Greening economic activity means implementing the idea of "green" activities, that is, "green" economy = "green" industry = development of "green" technologies = compliance with "green" standards.

The measures (methods) of greening economic activity can include:

- improvement of existing production without capital replacement and introduction of new technologies (for example, reconstruction of systems for trapping pollutants at industrial enterprises [3, 4, 5]; introduction of resource-saving and waste-free technologies and the latest circulating water supply systems at enterprises, etc.) [6];

- improvement of measures allowing the rational use of natural resources [7, 8];

- legal measures (establishment and consolidation of standards and plans for the gradual reduction of pollution from industrial facilities to levels corresponding to the best environmentally friendly world technologies, the introduction of digital technologies into production) $[9,10]$;

- financial measures (attraction of budgetary funds to finance environmental protection activities, etc.).

Socialization of economic activity means not just the introduction of short-term social measures to relieve social tensions that arise both in connection with economic reasons (decrease in income) and in balance with the ecological sphere, namely, in the use of the natural environment to the detriment of the local population, but the construction of longterm policy taking into account the specified circumstances.

The measures (methods) of socialization of economic activity can include:

- clear consolidation in the legislation of the rights of the local population to the natural environment and privileges from its use;

- an increase in the degree of involvement of natural resources in social forms of use (mass involvement of the local population in work in the natural resource industry);

- improving the state of affairs in the field of labor protection of workers in the natural resource industry; increase in the level of wages - equalizing the level of wages in cities and rural areas [11];

- availability of social infrastructure (medical, educational and other institutions) in remote natural resource regions.

We believe that such measures will make it possible to more quickly achieve the goals of sustainable development in the environmental and social spheres precisely due to the building of a balance of environmental and social interests.

\section{Conclusions}

Features of the current stage in achieving sustainable development goals are in the implementation of all planned activities in the context of the global environmental crisis and social tension.

As a result of the study, the authors of the article proposed tools for enhancing the process of achieving sustainable development goals in the form of "greening" and "socialization" of economic activity. In our opinion, this will make it possible to solve in a balanced way the current problems of social and ecological development and preserve a favorable environment and natural resource potential. 


\section{References}

1. The-Sustainable-Development-Goals-Report-2020, https://unstats.un.org/

2. E. Abanina, Yu. S. Sergeenko, Iu. Litvinova, Yu. M. Nikitenko, N. Bobrakova, SHS Web of Conferences, 93 (2021)

3. V. L. Abramov, F. A. Kodirov, A. A. Gibadullin, V. N. Nezamaikin, O. I. Borisov and N. V. Lapenkova, J. Phys: Conf. Ser., 1515 (2020)

4. V. N. Zakharov, V. Y. Linnik, Y. N. Linnik, A. B. Zhabin, Mining Informational and Analytical Bulletin, 5 (2019)

5. A. V. Nikonorova, P. V. Stroev, D. E. Morkovkin, O. N. Bykova, N. I. Isaichikova, A. A. Kvak and O. O. Skryabin, J. of Interdisciplinary Research, 9 (2020)

6. A. Caverzan, M. L. Tornaghi, P. Negro, IOP Conf. Ser: Mater. Sci. Eng., 442 (2018)

7. A. A. Gibadullin, et al, IOP Conf. Ser.: Earth Environ. Sci., 421 (2020)

8. L. M. Musina, M. U. Neucheva, IOP Conf. Ser.: Earth Environ. Sci., 107 (2018)

9. K. A. Artamonova, et al, J. Phys.: Conf. Ser., 1515 (2020)

10. D. E. Morkovkin, et al, J. Phys.: Conf. Ser. 1399 (2019)

11. A. Shilovtsev, N. Sorokina, K. Stozhko, J. L. L. Garcia, E3S Web of Conferences, 222 (2020) 